\title{
Chitosan/silica composite membrane: Performance on water permeability and rejection of lead(II) ion from aqueous solution
}

\author{
Nurshahida Rosdi a, Mohd Nazri Mohd Sokri a, b, ${ }^{*}$, Muhammad Ikmal Fitri Hairul Anuar b, Nor Asikin \\ Awang ${ }^{\text {a }}$, Norhana Mohamed Rashid ${ }^{\mathrm{b}}$ \\ ${ }^{a}$ Advanced Membrane Technology Centre (AMTEC), Universiti Teknologi Malaysia, 81310 UTM Johor Bahru, Johor, Malaysia \\ b School of Chemical and Energy Engineering, Faculty of Engineering, Universiti Teknologi Malaysia, 81310 UTM Johor Bahru, Johor, Malaysia \\ * Corresponding author: nazrisokri@utm.my
}

Article history

Received 11 Mac 2019

Revised 23 May 2019

Accepted 29 December 2019

Published Online 15 June 2020

\begin{abstract}
Heavy metal such as lead can be classified as non-biodegradable inorganic pollutants which can contaminate the soils, ground water, sediments and surface water. It cannot be broken down or decomposed by living organism and can continue to exist over a prolonged period, generating harmful effects to the living things. Thus, lead removal is necessary in order to reduce the amount of heavy metals contaminated in water. The purpose of this study was to fabricate chitosan/silica based composite membrane for removal of $\mathrm{Pb}(\mathrm{II})$ metal ions from aqueous solution by membrane filtration technique. The composite membranes were characterized in terms of morphological studies and functional group analysis by using Scanning Electron Microscopy (SEM) and Fourier Transform Infrared-Attenuated Total Reflectance (FTIR-ATR) analysis, respectively. The membrane permeation performance, in terms of water permeability and rejection of $\mathrm{Pb}$ (II) ions from aqueous solution, was conducted by using membrane permeation system. SEM images illustrated that the presence of macrovoids on the cross-section of the chitosan/silica composite membrane has improved the morphology of pure chitosan membrane and assisted in the rejection of $\mathrm{Pb}(\mathrm{II})$ ions. Meanwhile, FTIR-ATR spectra showed the presence of new adsorption peaks, contributed by silica interaction with hydroxyl group of chitosan. The addition of silica to chitosan membrane has significantly enhanced the pure water permeability from $37.36 \mathrm{~L} / \mathrm{m}^{2} \mathrm{~h}$ to $42.43 \mathrm{~L} / \mathrm{m}^{2} \mathrm{~h}$. Furthermore, the rejection of $\mathrm{Pb}$ (II) metal ions by chitosan/silica composite membrane was slightly higher compared to pure chitosan membrane with the removal efficiency of $13.78 \%$ at 0.5 bar applied pressure. These findings indicate the potential use of silica to improve chitosan membrane properties and reduce heavy metal pollution in water.
\end{abstract}

Keywords: Chitosan, silica, composite membrane, lead(II), rejection

\section{INTRODUCTION}

Contaminants of heavy metals in wastewater, as a result of industrial and technological advancements, become a major concern nowadays. Although some of the heavy metals are essential for growth of living organisms, but mostly, they possess toxic and carcinogenic properties which can harm living things and environmental system (Zamani et al., 2012). Lead metal $(\mathrm{Pb})$ is one of the examples of harmful heavy metals which can be found in any aqueous wastewater effluent from industries (Nasef and Yahaya, 2009). It will be deposited on soil and water before reaching human via food chain (Järup et al., 2003). However, its toxicity is depended on the concentration levels of $\mathrm{Pb}$ (II) metal ions in the ecosystem. World Health Organization (WHO) allows the limit amount of $\mathrm{Pb}$ (II) metal ions to be discharged into surface water, which is $0.015 \mathrm{ppm}$ (Cotruvo et al., 2011).

With this concern, different techniques have been employed for removal of heavy metal ions from wastewater. It includes chemical precipitation, ion exchange, adsorption, membrane filtration, flotation, coagulation, flocculation and electrochemical treatment (Carolin et al., 2017; Azimi et al., 2017). In recent years, membrane filtration receives great attention from researchers because of its capability to remove suspended solid, organic compound and inorganic contaminants (Gunatilake, 2015). Besides, membrane can be simply designed with low production cost and excellent efficiency for the removal of metal ions ( Habiba et al., 2017).

Presently, natural bio-polymer chitosan has been widely used in membrane fabrication to remove heavy metals since chitosan possesses high quantity of amino and hydroxyl groups, which makes it significant in adsorption process (Budnyak et al., 2015). However, chitosan-based membranes needs further modification due to their low structural and physical properties, which limits their potential applications in membrane filtration systems (Behera et al., 2017; Rekik et al., 2017)

Rice husk is an agricultural waste derived from rice production. In Malaysia, the production of rice increases every year as well as the production of rice husk. This situation may lead to the space limitations when the waste is disposed to landfills (Pode, 2016). In a previous study, Battegazzore et al. (2014) discovered about $80-90 \%$ of silica can be obtained from incineration process of rice husk. The obtained silica can be used in various applications such as plastic and rubber reinforcement. However, silica generally can be converted into 
sodium silicate since it is more convenient to be used in wastewater treatment applications (Pode, 2016). Therefore, sodium silicate tends to be added in chitosan membrane to enhance the properties of chitosan membrane.

In this study, chitosan/silica composite membranes were fabricated using sodium silicate that derived from rice husk ash and characterized using SEM and FTIR-ATR. Then, the membranes were used to investigate the rejection of $\mathrm{Pb}$ (II) metal ions from aqueous solution via filtration.

\section{EXPERIMENTAL}

\section{Materials}

Rice husks were collected from Kilang Beras Jelapang Selatan (M) Sdn Bhd., Muar, Johor. A commercial chitosan in powder form (75-85\% deacetylated) with medium molecular weight $(190,000-$ 310, 000 Da.) was purchased from Sigma Aldrich ${ }^{\circledR}$. Acetic acid glacial $(\geq 99.85 \%)$ that acted as a solvent was acquired from $\mathrm{HmbG}^{\circledR}$ Chemicals. Both, sodium hydroxide $(\mathrm{NaOH}, 99 \%)$ and lead(II) nitrate solution $\left(\mathrm{Pb}\left(\mathrm{NO}_{3}\right)_{2}, \geq 99.5 \%\right)$ were obtained from QRëC ${ }^{\mathrm{TM}}$.

\section{Synthesis of silica source}

White rice husk ash that obtained from incineration process of rice husk at $600^{\circ} \mathrm{C}$ for $3 \mathrm{~h}$ was mixed with $1 \mathrm{M} \mathrm{NaOH}$ solution (molar ratio $\mathrm{Si} / \mathrm{Na}=1$ ) by heating and stirring the solution. The product, white-grey powder was sintered at $800^{\circ} \mathrm{C}$ for $2 \mathrm{~h}$ to produce solid sodium silicate, $\mathrm{Na}_{2} \mathrm{SiO}_{3}$. This sodium silicate was then used as a silica source in the fabrication of chitosan/silica composite membranes.

\section{Preparation of chitosan/silica composite membranes}

Sodium silicate was first dissolved in $50 \mathrm{~mL}$ of $0.1 \mathrm{M}$ acetic acid. $1 \mathrm{~g}$ of chitosan was later added and stirred until it was completely dissolved to obtain homogenous chitosan/silica solution, followed by sonication for $90 \mathrm{~min}$. A yellowish colour dope solution was casted on the clean glass plate and left at room temperature for $24 \mathrm{~h}$ to allow the solvent to evaporate. Then, the dried membranes were immersed into $1 \mathrm{M} \mathrm{NaOH}$ solution to make it neutral. Distilled water was used to remove the excess of $\mathrm{NaOH}$ prior to drying at room temperature. The preparation of chitosan/silica dope solution was followed the formulation as described in Table 1.

Table 1 Chitosan/silica membrane formulation.

\begin{tabular}{lll}
\hline Sample & $\begin{array}{l}\text { Chitosan } \\
(\mathbf{g})\end{array}$ & $\begin{array}{l}\text { Sodium silicate } \\
(\mathbf{g})\end{array}$ \\
\hline CHSi0 & 1 & 0 \\
CHSi3 & 1 & 0.03 \\
CHSi6 & 1 & 0.06 \\
CHSi9 & 1 & 0.09 \\
\hline
\end{tabular}

\section{Membrane characterization}

The morphologies of the composite membranes were observed under Scanning Electron Microscopy (SEM), (Hitachi, TM3000 model). All the samples were cut into smaller pieces and sputter with gold prior to observation.

The determination of functional groups in chitosan/silica composite membranes was recorded by using Fourier Transform Infrared-Attenuated Total Reflectance Spectrometer (FTIR-ATR), (JASCO, FT/IR-4200IF). The samples were scanned at a wavelength of 400 to $4000 \mathrm{~cm}^{-1}$.

The concentration of $\mathrm{Pb}(\mathrm{II})$ metal ions was measured by Atomic Adsorption Spectroscopy (AAS), (Shimadzu AAS, AA-7000 model). All the reported data was in the average of five replicates.

\section{Membrane performance}

The pure water permeability (PWP) and $\mathrm{Pb}$ (II) ion rejection were measured using membrane filtration process (effective membrane area: $10.18 \mathrm{~cm}^{2}$ ) at room temperature with applied pressure of 0.5 bar. The membrane samples were firstly pressurized at 1 bar for $30 \mathrm{~min}$ to avoid any compaction effects. Meanwhile, the output pressure was exposed to the atmospheric conditions. In case of PWP, distilled water was used to circulate through the membrane permeation system until constant flux was observed. Meanwhile, for rejection of $\mathrm{Pb}$ (II) metal ions from aqueous solution, permeate samples were collected after 30 minutes of operation with feed containing $10 \mathrm{ppm}$ of $\mathrm{Pb}$ (II) solution. As previously described (Ma et al., 2012), flux (F) and rejection $(\mathrm{R})$ were calculated by using equations, in which $\mathrm{F}$ was calculated using Eq. (1).

$$
F\left(L m^{-2} h^{-1}\right)=V /(A \times t)
$$

Where, $\mathrm{F}$ is the flux, $\mathrm{V}(\mathrm{L})$ is the volume of permeate through the membrane, while $\mathrm{A}\left(\mathrm{m}^{2}\right)$ and $\mathrm{t}(\mathrm{h})$ are the area of the membrane and time, respectively. Rejection of $\mathrm{Pb}(\mathrm{II})$ metal ions was calculated by Eq. (2).

$$
R(\%)=\left(1-C_{P} / C_{F}\right) \times 100
$$

Where, $R$ is the percent of rejection. $C_{P}\left(\mathrm{mg} \mathrm{L}^{-1}\right)$ and $\mathrm{C}_{\mathrm{F}}\left(\mathrm{mg} \mathrm{L}^{-1}\right)$ are the lead concentration in permeate and feed stream, respectively. All recorded data was the average values of five replicates.
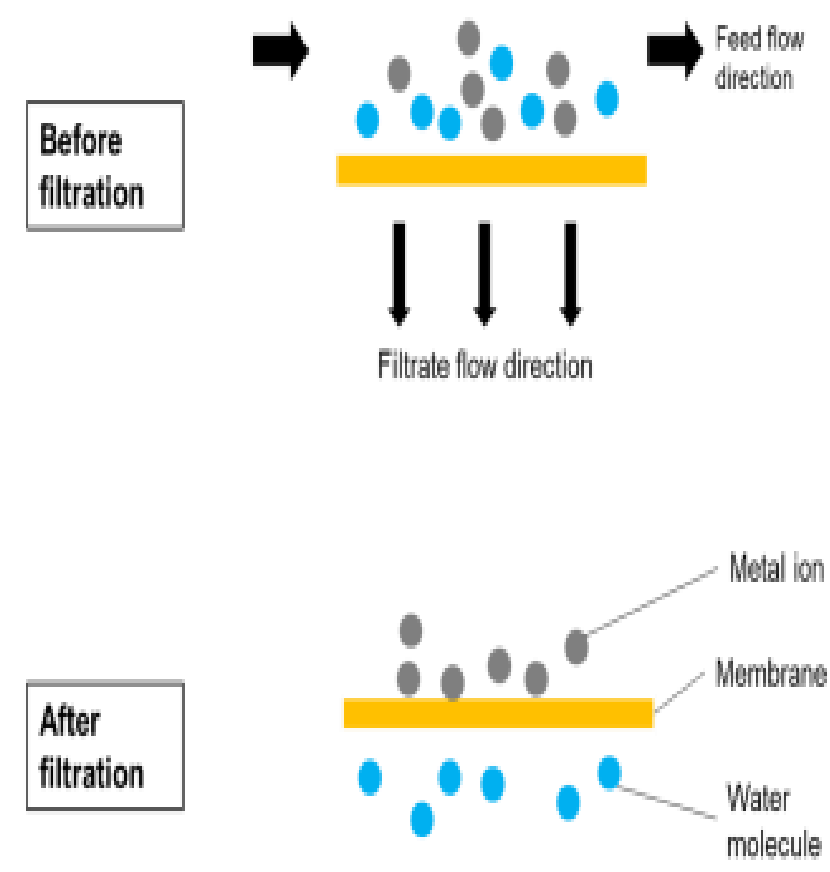

Fig. 1 Schematic diagram of heavy metal ion removal via membrane filtration process.

\section{RESULTS AND DISCUSSION}

\section{SEM analysis}

The surface and cross-section morphologies of the membranes were presented in Figs. 2 and 3, respectively. Based on Fig. 2, the pure chitosan membrane ( $\mathrm{CHSi0})$ showed smooth surface and the presence of pore could not be observed. Similar result was also reported by (He et al., 2016). In addition, based on the cross-section of SEM image, it was confirmed that the CHSi0 membrane possessed dense structure (Fig. 3). Initially, as sodium silicate was added to form chitosan/silica composite membranes, no significant improvement in structural characteristics could be observed for CHSi3 and CHSi6, as compared to $\mathrm{CHSiO}$ membrane. However, as sodium silicate content was increased, the presence of microvoids could be observed in the inner structure of CHSi9, as displayed in Fig. 3, indicating that the addition of sodium silicate was able to improve the morphology of chitosan membrane in which the presence of microvoids might be useful in assisting the rejection of $\mathrm{Pb}$ (II) metal ions from aqueous solution. 

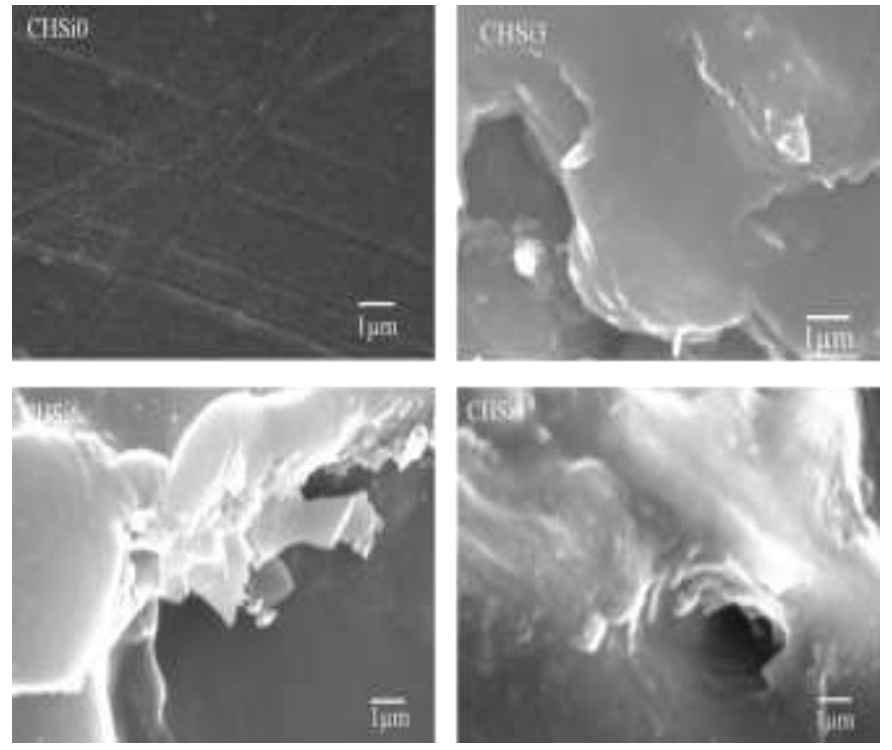

Fig. 2 SEM image of the surface of the membranes.
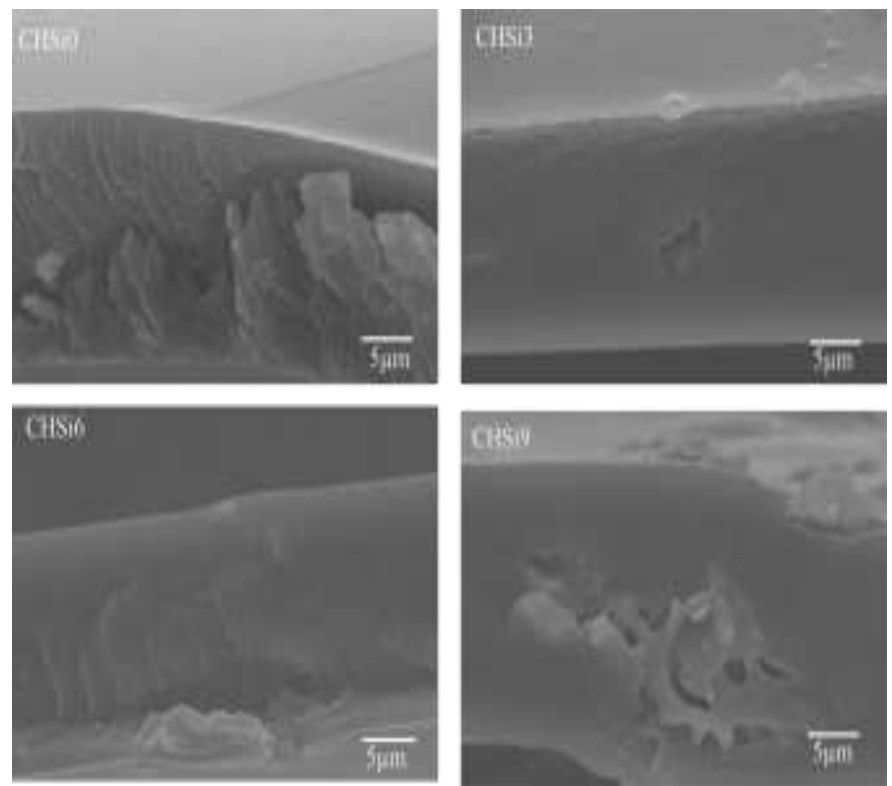

Fig. 3 SEM image of the cross-section of the membranes.

\section{FTIR-ATR analysis}

The fabrication of chitosan/silica composite membranes involved the changes of functional groups. Therefore, the pure chitosan membrane and composite membranes were characterized using FTIRATR as shown in Fig. 4. Broad adsorption bands were observed at 3363 and $3282 \mathrm{~cm}^{-1}$ which corresponded to the vibration of $\mathrm{O}-\mathrm{H}$ hydroxyl groups that bonded to carbon atoms and silica atoms (Budnyak et al., 2015). The stretching vibrations of $\mathrm{N}-\mathrm{H}$ were overlapped with the adsorption band of $\mathrm{O}-\mathrm{H}$ at the wavenumber area of $3500-3100 \mathrm{~cm}^{-1}$ and the intensity of the peak was decreased in the CHSi9 membrane spectrum due to the interaction of silica with amide and hydroxyl groups of chitosan. The $\mathrm{C}-\mathrm{H}$ stretching vibration peaks were recorded at 2904 and $2891 \mathrm{~cm}^{-1}$ (Abu-Saied et al., 2017). The bands at 1645,1560 and $1550 \mathrm{~cm}^{-1}$ of both spectra indicated the deformation of $\mathrm{N}-\mathrm{H}$ bond of amino groups (Budnyak et al., 2015). The peaks of $\mathrm{C}-\mathrm{H}$ bending vibrations were observed at 1381 and $1367 \mathrm{~cm}^{-1}$. Besides, the band at $1024 \mathrm{~cm}^{-1}$ represented the vibrations of $\mathrm{C}-\mathrm{O}$ of $\mathrm{CH}-\mathrm{OH}$ groups (Mahatmanti et al., 2016). The new adsorption peak was observed at $1041 \mathrm{~cm}^{-1}$ and a shoulder was detected at $779 \mathrm{~cm}^{-1}$ of CHSi9 membrane, corresponding to the asymmetric Si-O-Si and symmetric Si-O-Si bonds of chitosan/silica membrane, respectively (He et al., 2016).

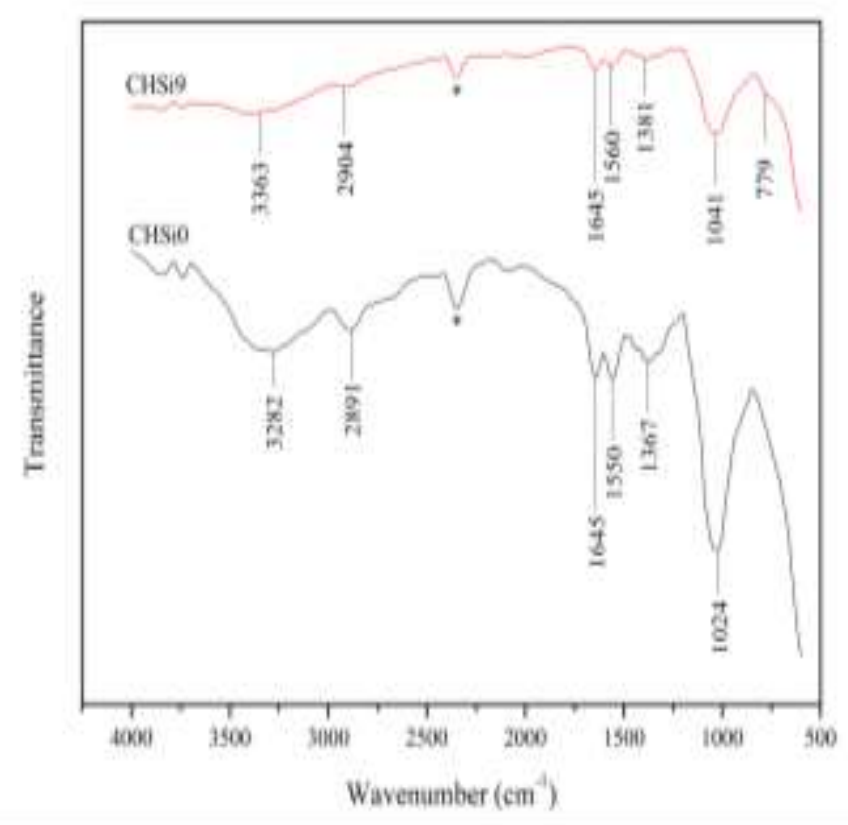

Fig. 4 FTIR-ATR spectra of the $\mathrm{CHSi0}$ and $\mathrm{CHSi9}$ membranes. ( ${ }^{*}$ indicating background, adsorption due to $\mathrm{CO}_{2}$ )

\section{Membrane performance}

The membrane permeation performance data with different silica contents was reported in Table 2. As presented, the flux and rejection of $\mathrm{Pb}$ (II) metal ions were increased with the addition of silica. This results was expected based on the SEM images and spectra from FTIR analysis. Since CHSi9 membrane contained microvoids, it allowed more water molecules to pass through the membrane (Vlotman et al., 2018). Furthermore, the amount of active sites for $\mathrm{Pb}$ (II) metal ions to adsorb onto the surface of the membrane during the filtration process was also increased. Thus, the rejection of $\mathrm{Pb}(\mathrm{II})$ metal ions from aqueous solution was also increased.

Table 2 Membrane permeation performance.

\begin{tabular}{lll}
\hline Sample & $\begin{array}{l}\text { Water flux } \\
\left(\mathbf{L} / \mathbf{m}^{2} \mathbf{h}\right)\end{array}$ & $\begin{array}{l}\text { Rejection of } \mathrm{Pb}(\mathrm{II}) \\
(\%)\end{array}$ \\
\hline CHSiO & 37.36 & 11.72 \\
CHSi9 & 42.43 & 13.78 \\
\hline
\end{tabular}

\section{CONCLUSION}

In this study, the chitosan/silica composite membranes were succesfully fabricated. Based on the characterization results, it was found that the presence of silica in chitosan/silica composite membrane enhanced the physical and structural characteristics of chitosan membrane. The composite membrane provided more active sites and created microvoids to increase $\mathrm{Pb}$ (II) metal ions rejection through membrane. The rejection of $\mathrm{Pb}$ (II) ions showed an improvement in the chitosan/silica composite membrane as compared to pure chitosan membrane. Therefore, it was suggested that the silica derived from rice husk ash could be used to improve the properties of chitosan based membrane and enhanced the rejection of $\mathrm{Pb}$ (II) metal ions.

\section{ACKNOWLEDGEMENT}

This work was financially supported by the Universiti Teknologi Malaysia (UTM) under the Potential Academic Staff (PAS) grant (Project Number: Q.J130000.2746.02K66) and Higher Institution Centres of Excellence (HICoE) grant (Project Number: R.J090301.7846.4J257). 


\section{REFERENCES}

Abu-Saied, M. A., Wycisk, R., Abbassy, M. M., Abd El-Naim, G., ElDemerdash, F., Youssef, M. E., Bassuony, H., Pintauro, P. N. 2017. Sulfated chitosan/PVA adsorbent membrane for removal of copper and nickel ions from aqueous solutions-Fabrication and sorption studies. Carbo. Polym. 165, 149-158.

Azimi, A. Azari, A., Rezakazemi, M., Ansarpour, M. 2017. Removal of heavy metals from industrial wastewaters: A review. Chem. Bio. Eng. 4, 37-59.

Battegazzore, D., Bocchini, S., Alongi, J., Frache, A. 2014. Rice husk as biosource of silica: preparation and characterization of PLA-silica biocomposites. Royal Soc. Chem. 4, 54703-54712.

Behera, S. S., Das, U., Kumar, A., Bissoyi, A., Singh, A. K. 2017. Chitosan $/ \mathrm{TiO}_{2}$ composite membrane improves proliferation and survival of L929 fibrolast cells: Application in wound dressing and skin regeneration. International J. Biological Macromol. 98, 329-340.

Budnyak, T. M., Pylypchuk, I. V., Tertykh, V. A., Yanovska, B. S., Kolodynska, D. 2015. Synthesis and adsorption properties of chitosansilica nanocomposite prepared by sol-gel method. Nanoscale Res. Lett. 10,1-10

Budnyak, T. M., Tertykh, V. A., Yanovska, E. S., Kolodyńska, D., Bartyzel, A 2015. Adsorption of $\mathrm{V}(\mathrm{V}), \mathrm{Mo}(\mathrm{VI})$ and $\mathrm{Cr}(\mathrm{VI})$ oxoanions by chitosansilica composite synthesized by mannich reaction. J. Adsorpt. Sci. Technol. 33, 645-657.

Carolin, C. F., Kumar, P. S., Saravanam, A., Joshiba, G. J., Naushad, Mu. 2017. Efficient techniques for the removal of toxic heavy metals from aquatic environment: A review. J. Environ. Chem. Eng. 5, 2782-2799.

Cotruvo, J. Giddings, M., Jackson, P., Magara, Y., Festo Ngowi, A. V., Ohanian, E. 2011. Lead in drinking water. Backgr. Doc. For Development of WHO Guidel. for Drinking-water Quality. 4, 9-11.

Gunatilake, S. K. 2015. Method of removing heavy metals from industrial wastewater. J. Multidiscip. Eng. Sci. Stud. 1, 12-18.

Habiba, U., Afifi, A. M., Salleh, A., Bee, C. A. 2017. Chitosan/(polyvinyl alcohol)/zeolite electrospun composite nanofibrous membrane for adsorption of $\mathrm{Cr}^{6+}, \mathrm{Fe}^{3+}$ and $\mathrm{Ni}^{2+}$. J. Hazard. Mater. 322, 182-194.

He, X., Du, M., Li, H., Zhou, T. 2016. Removal of direct dyes from aqueous solution by oxidized starch cross-linked chitosan/silica hybrid membrane. Int. J. Bio. Macromol. 82, 174-181.

Järup, L. 2003. Hazards of heavy metal contamination. Br. Méd. Bull. 68, 167182.

Ma, X., Zhou, B., Gao, W., Qu, Y., Wang, L., Wang, Z., Zhu, Y. 2012. A recyclable method for production of pure silica from rice hull ash. Powder Technol. 217, 497-501.

Mahatmanti, F. W., Nuryono, Narsito. 2016. Adsorption of $\mathrm{Ca}(\mathrm{II}), \mathrm{Mg}$ (II), $\mathrm{Zn}$ (II) and Cd(II) on chitosan membrane blended with rice hull ash silica and polyethylene glycol. Indones. J. Chem. 16(1), 45-52.

Nasef, M. M., Yahaya, A. H. 2009. Adsorption of some heavy metal ions from aqueous solutions of Nafion 117 membrane. Desalination. 249, 677-681.

Pode, R. 2016. Potential applications of rice husk ash waste from rice husk biomass power plant. Renew. Sustainable Energy Rev. 53, 1468-1485.

Rekik, S. B., Gassara, S., Bouaziz, J., Deratani, A. Baklouti, S. 2017. Development and characterization of porous membranes based on kaolin/chitosan composite. Appl. Clay Sci. 143, 1-9.

Vlotman, D. E., Ngila, J. C., Ndlovu, T., Malinga, S. P. 2018. Hyperbranced polymer intergrated membrane for the removal of arsenic(III) in water. $J$. Membr. Sci. Res. 4, 53-62.

Zamani, A. A., Yaftian, M. R., Parizanganeh, A. 2012. Multivariate statistical assessment of heavy metal pollution sources of groundwater around a lead and zinc plant. Iranian J. Environ. Health Sci. Eng. 9, 1-10. 